ISSN: $1896-4087$

DOI: http://dx.doi.org/10.21784/ZC.2019.009

GLORIA ALVAREZ-BENITO

University of Seville, Spain

ANALI FERNANDEZ-CORBACHO

University of Huelva, Spain

FRANCISCO HERRERO MACHANCOSES

Universitat Jaume I de Castellón, Spain

MARIA DEL CARMEN FONSECA-MORA

University of Huelva, Spain

\title{
Cognitive and language-based disabilities of children diagnosed with cancer
}

\section{Poznawcze i językowe zaburzenia u dzieci z rozpoznaniem raka}

\begin{abstract}
:
The survival rate of children suffering from cancer has increased, but collateral effects have been observed. A mixed-method was used to evaluate cancer children's language and cognitive abilities. Variables such as IQ and verbal comprehension, perceptual reasoning, working memory and processing speed were tested. Furthermore, a semi-guided 30-minute-long conversation on everyday matters was used for linguistic evaluation. Results confirm that language problems were present at phonological, lexical-semantic, structural or syntactic, pragmatic and non-verbal levels.

Keywords: childhood cancer, language disabilities, cognitive evaluation, discourse analysis, communication abilities, language use

\section{Streszczenie:}

Wskaźnik przeżywalności dzieci cierpiących na raka wzrósł, ale zaobserwowano efekty dodatkowe. Metoda mieszana została wykorzystana do oceny języka i zdolności poznawczych dzieci chorych na raka. Przetestowano zmienne, takie jak IQ i rozumienie werbalne, rozumowanie percepcyjne, pamięć roboczą i szybkość przetwarzania. Ponadto do oceny językowej użyto 30-minutowej, częściowo sterowanej rozmo-
\end{abstract}


Gloria Alvarez-Benito et al. - Cognitive and language-based disabilities...

wy na temat spraw codziennych. Wyniki potwierdzają, że problemy językowe były obecne na poziomach fonologicznych, leksykalno-semantycznych, strukturalnych lub syntaktycznych, pragmatycznych i niewerbalnych.

Słowa kluczowe: rak dziecięcy, zaburzenia językowe, ocena poznawcza, analiza dyskursu, zdolności komunikacyjne, użycie języka

\section{Introduction}

Child language disorders have frequently been studied related to autism, hearing loss or dyslexia ${ }^{1}$ but not much has been said about the language problems children suffering from cancer encounter. This could be related to the fact that the survival rate of children diagnosed with a tumour has increased up to more than $70 \%$ in high-income countries in the last decades, but that school and social integration of these survivors has not yet been fully related to language and communication issues. Side effects have been mainly compromised to other effects of the tumour and the treatment that affect their life quality. In fact, social, emotional, behavioral, and neurocognitive domains have been explored. Thus, the experiences of cancer in children and adolescents have been described to confirm that effects were not only related to health ${ }^{2}$. The patients mentioned negative effects such as a sense of transient and permanent discomfort and a disruption of life or relationships. An analysis ${ }^{3}$ of the cognitive and psychosocial functioning of preschool-aged children with cancer found significant risk of deficits in intellectual, adaptive, and preacademic functioning. The vulnerability of children with cancer to significant academic un-

\footnotetext{
2017.

${ }^{1}$ R. G. Schwartz, (ed.), Handbook of child language disorders. Routledge, New York

2 B. Novakovic et al., Experiences of cancer in children and adolescents, „Cancer nursing" 1996, no. 19 (1), s. 54-59.

3 V. W. Willard et al., Cognitive and Psychosocial Functioning of Preschool-Aged Children with Cancer, ,Journal of Developmental \& Behavioral Pediatrics” 2017, no. 38 (8), s. 638-645.
} 
derachievement was also studied ${ }^{4}$ by analysing their IQs, reading comprehension, mathematics, and spelling skills.

Other side effects of cancer have also been observed in very young and young children. In a review, the wide range of areas affected have been pointed out ${ }^{5}$ - neurocognitive, social, emotional, physical and environmental. Among these collateral effects, neurocognitive impairments after brain cancer treatment have been mostly studied. In this vein, there is an analysis ${ }^{6}$ of 29 studies that confirm negative neurocognitive effects on long-term survivors. Their meta-analysis directly points to negative sequelae in terms of children's intellectual functioning and attentiveness that imply difficulties in acquiring knowledge and abilities at the same rate as their classmates. The reasons for these late effects are not yet fully understood ${ }^{7}$, but decrease in IQ tests has been related to white matter, to the damage of neural networks after surgery ${ }^{8}$ or to white matter loss due to radiation'.

Studies on effects of childhood cancer have also been approached from the perspective of trying to find remedial strategies to lower or even reverse those effects. For example, brain tumour survivors' attentional and working memory deficits have been addressed ${ }^{10}$. In this study the researchers used a home-based computerized intervention

${ }^{4}$ J. S. Ott et al., Childhood cancer and vulnerability for significant academic underachievement, „Journal of learning disabilities” 1982, no. 15 (6), s. 363-365.

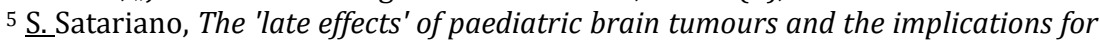
education setting, „Educational \& Child Psychology” 2016, no. 33 (1), s. 20-23.

${ }^{6}$ M. A. de Ruiter et al., Neurocognitive consequences of a paediatric brain tumour and its treatment: a meta-analysis, „Developmental Medicine \& Child Neurology” 2013, s. 415.

7 M. D. Ris et al., Measurement of neurodevelopmental changes in children treated with radiation for brain tumors: what is a true 'baseline?, „The Clinical Neuropsychologist" 2017, no. 31 (2), s. 307-328.

$8 \mathrm{~N}$. Scantlebury et al., White matter and information processing speed following treatment with cranial-spinal radiation for pediatric brain tumor, „Neuropsychology” 2016, no. 30 (4), s. 425.

${ }^{9} \mathrm{~S}$. Bells et al., Changes in white matter microstructure impact cognition by disrupting the ability of neural assemblies to synchronize, „Journal of Neuroscience” 2017, no. 37 (34), s. 8227-8238.

$10 \mathrm{~K}$. K. Hardy et al., Working memory training in survivors of pediatric cancer: a randomized pilot study „Psycho-Oncology” 2013, no. 22 (8), s. 1856-1865. 
Gloria Alvarez-Benito et al. - Cognitive and language-based disabilities...

programme designed to improve users' visuo-spatial and auditory working memory skills. Although their study was not conclusive, children with higher cognitive abilities at baseline seemed to benefit more.

Brain tumour survivors' reading-related neural activation has also been examined 11 . In their functional magnetic resonance imaging (fMRI) study, five fMRI tasks such as Rapid Automatized Naming, Continuous Performance Test using faces and letters, orthographic and phonological processing of letter pairs, implicit word reading, and story reading were used. In addition, a measure of phonemic awareness, the pronunciation of unfamiliar non-words and the children's reading fluency, were also evaluated. According to their results, survivors scored lower in reading fluency, phonemic awareness and in the pronunciation of nonwords. As a general conclusion, this study confirmed that impaired reading may underlie brain tumour survivors' academic failure and that remedial interventions can mitigate survivors' learning difficulties. Similarly, specific interventions with children diagnosed with cancer in school settings have been recommended ${ }^{12}$.

Regarding the methodological approach, a study ${ }^{13}$ added an interesting new perspective into the field of childhood cancer effects. In view of the evidence-based assumption that survivors' cognitive limitations may restrict their participation in questionnaire-based studies, the researchers proposed a mixed-method study (questionnaires plus interviews) to analyse their participants' quality of life. While the quantitative results showed that $95 \%$ of the survivors did not exhibit increased risk for depression, their qualitative results indicated that survivors were more concerned with social aspects than with func-

11 P. Zou et al., Functional MRI in medulloblastoma survivors supports prophylactic reading intervention during tumor treatment, „Brain imaging and behavior” 2016, no. 10 (1), s. 258-271.

12 G. Thompson, Supporting Communication Disorders: A Handbook for Teachers and Teaching Assistants. David Fulton Publishers, London 2013.

13 M. E. Guun et al., Quality of life and late-effects among childhood brain tumor survivors: a mixed method analysis, „Psycho-Oncology” 2016, no. 25 (6), s. 677-683. 
tionality for their quality of life. The authors of this study mentioned that "half of the survivors had needed long-lasting extra tutoring at school” 14 and that "survivors especially at risk for decreased quality of life are those suffering from insufficient supportive social network" 15 .

This capacity of creating social networks is related to people's communication skills and these communication skills are highly language-dependent. Thus, the lack of communication skills may be due to language disorders. Language problems have been studied in children and young people with learning or language disabilities and with physical or mental disorders. Attention has also been paid to problems with speech mechanism due to head and neck cancer ${ }^{16}$. As regards children with brain tumours, studies usually focus on evaluating their cognitive, adaptive and social abilities, in spite of the importance of language problems observed in this population. Nonetheless, some studies have shown that radiotherapy and tumours in the right cerebellar hemisphere are associated with language disorders. Deficits in high-level language skills, such as the ability to interpret a respond to a conversation, have been identified in children with tumour in the right cerebellum ${ }^{17}$. In this vein, a focus on the narrative skills of children with brain cancer has been recommended ${ }^{18}$.

Child language disorders have traditionally been analysed from morphosyntactic, semantic, lexical and pragmatic perspectives ${ }^{19}$ but

\footnotetext{
14 Ibidem, s. 681.

15 Ibidem, s. 682.

16 T. Bressmann, Speech Disorders Related to Head and Neck Cancer Laryngectomy, Glossectomy, and Velopharyngeal and Maxillofacial Deficits, [in:] J. S. Damico, N. Müller, M. J. Ball (Eds.), The Handbook of Language and Speech Disorders. Blackwell, Oxford 2010, s. 497-522.

17 K. Docking, B. Murdoch, R. Suppiah, The impact of a cerebellar tumour on language function in childhood, „Folia Phoniatrica et Logopaedica” 2007, no. 59 (4), s. $190-200$.

18 K. Docking, N. Munro, T. Marshall, L. Togher, Narrative skills of children treated for brain tumours: The impact of tumour and treatment related variables on microstructure and macrostructure, „Brain Injury” 2016, no. 30 (8), s. 1005-1018.

19 R. G. Schwartz, (Ed.)., Handbook of child language disorders. Routledge, New York 2017.
} 
Gloria Alvarez-Benito et al. - Cognitive and language-based disabilities...

these linguistic perspectives have not been sufficiently considered in analysing the discourse of children with brain tumours. This study seeks to identify the cognitive and language-based disabilities of children who have been diagnosed with cancer. Interested in exploring neurocognitive and linguistic characteristics of young cancer children, we used a mixed-method approach: a standardized neurocognitive test and a semi-structured interview. This study hypothesises that testing children's cognitive functions is not enough to identify their language and communication disabilities and that discourse analysis reveals linguistic aspects related to phonology, lexicon, syntax, pragmatics and even non-verbal communication that need to be considered. Identifying these language problems is of utmost importance for language experts to further develop appropriate recovery strategies and training programmes for school and social integration of children survivors.

\section{Material and methods}

\subsection{Participants}

The children who participated in this study were hospitalized in the pediatric cancer center of a large public hospital. All of those who had been diagnosed with a brain tumour were selected for the study; however, the sample size was finally reduced because of the following reasons:

- Some of the children were too young and not mature enough for a cognitive and linguistic evaluation;

- Some children were in extremely poor physical condition;

- Some children, who had been included, died during the study.

Finally, participants for this analysis were 12 Spanish children diagnosed with central nervous system (CNS) cancer ( 7 boys and 5 girls) between 6 and 14 years old at the time of assessment. Regarding age, no significant differences were observed based on intelligence quotient (IQ) and cognitive subscales scores between children 
younger than 11 and 11 or older ( $\mathrm{p}_{\mathrm{Umw}}>.05$ ). The same was found in relation to sex ( $\mathrm{p}_{\mathrm{Umw}}>.05$ ). Parents and teachers confirmed that none of the children had shown language or learning problems prior to treatment. Besides, all children had finished the radiotherapy treatment, but one of them had still one round of chemotherapy to finish all treatments.

\subsection{Procedure and research instruments}

After approval from the parents, children were tested and interviewed. A mixed-method was used to evaluate children diagnosed having a tumour. On the one hand, WISC-IV was administered for cognitive evaluation after cancer diagnosis. Variables such as the child's IQ and the scores in the areas of verbal comprehension (VC), perceptual reasoning (PR), working memory (WM) and processing speed (PS) were tested. On the other hand, for linguistic and communication evaluation, a semi-guided 30-minute-long conversation on everyday matters was performed (see appendix I). The language expert asked children to describe their daily routines, their relationship with other children at school, the subjects they like most, their relationship with other family members, their hobbies, and the things or activities they do not like. The test and the interview were administered in two different days with a week between each of them. Regarding statistical analysis, in order to mitigate the impact of the small sample size on the results, Wilcoxon signed rank test with Bootstrapping, following the Monte Carlo simulation method based on 10000 samples, were carried out; as these analyses are designed to work with reduced sample sizes.

\section{Results}

\subsection{Cognitive difficulties}

Descriptive statistics for age, IQ, VC, PR, WM and PS are available in Table 1. Most cognitive scores were in the low average range and 
Gloria Alvarez-Benito et al. - Cognitive and language-based disabilities...

consistently about 1 SD below the normative mean, with the exception of VC. Besides, in our sample, median score for PS differed 2 SD from the IQ normative mean (100) in WISC-IV. Wilcoxon signed rank test with Bootstrapping, following the Monte Carlo simulation method based on 10000 samples, were carried out to test the null hypothesis that the median of the variables is 100 . Only significative differences in the PS variable $(\mathrm{Md}=70, \mathrm{Sd}=21.62, \mathrm{p}=.012,99 \%$ IC $=[.009$, .014]) were found. Medium effect size was observed for all variables except for VC $(r=.068)$, which had a very small effect size.

Table 1. WISC-IV Descriptive statistics and normative comparison

\begin{tabular}{|l|c|c|c|c|c|c|}
\hline & $\begin{array}{c}\text { Age at } \\
\text { evaluation }\end{array}$ & IQ & VC & PR & WM & PS \\
\hline $\bar{X}$ & 11.69 & 85.50 & 99.08 & 84.83 & 87.92 & 79.50 \\
\hline Md & 12.46 & 89.50 & 103 & 94 & 94 & 70 \\
\hline Min & 6.07 & 44 & 45 & 51 & 50 & 50 \\
\hline Max & 15.74 & 121 & 134 & 112 & 110 & 117 \\
\hline Range & 9.67 & 77 & 89 & 61 & 60 & 67 \\
\hline Sd & 3.32 & 24.99 & 24.83 & 22.84 & 19.33 & 21.62 \\
\hline P & & .075 & .813 & .091 & .060 & $.016^{*}$ \\
\hline p (montecarlo) & & .085 & .830 & .098 & .063 & .012 \\
\hline IL 99\% & & .077 & .820 & .090 & .057 & .009 \\
\hline SL 99\% & & .092 & .840 & .105 & .069 & .014 \\
\hline E.S. (r) & & .513 & .068 & .488 & .544 & .694 \\
\hline
\end{tabular}

Source: Own study on the basis of the data gathered from the participants

\subsection{Language difficulties}

Discourse analyses revealed that children diagnosed with CNS cancer present a variety of language difficulties associated both with reception and production levels. The language problems identified were present at different levels of analysis: phonological, lexical- 
semantic, structural or syntactic, pragmatic and non-verbal. More concretely, 11 (91.7\%) children of our sample exhibited problems in understanding structural ambiguity and $11(91.7 \%)$ in understanding instructions with complex sentences; 10 (83.3\%) showed impaired lexical access, while $8(66.7 \%)$ had problems in understanding lexical ambiguity. Wrong use of language in context was observed in 6 (50\%) children of our sample. Finally, 5 (41.7\%) children exchanged consonants in words, 3 (25\%) children inserted an intrusive consonant in some words, and 3 (25\%) showed problems in articulating words.

In order to observe if sex and age factors could be influential variables, a Chi square test was used. Regarding the sex factor, a dependence relationship was observed with the category "understanding lexical ambiguity" $\left(\chi^{2}{ }_{(1)}=8.4, \mathrm{Cc}=.642, \mathrm{p}=.004,95 \%\right.$ IC $\left.[.007, .013]\right)$ while no relationship was found with the remaining language variables such as impaired lexical access, articulation, consonant exchanges, consonant insertions, understanding complex sentences and structural ambiguity, and use of language in context. No dependence relationship was found for age.

We have adopted two basic approximations to the language difficulties encountered: difficulties in language reception and difficulties in language production. The first one includes structural or syntactic and pragmatic dysfunctions. Language production problems are described according to phonological disorders, lexical and semantic, and morphological dysfunctions. The category „wrong use of language” was observed in the receptive and productive domains. Finally, nonverbal strategies used to compensate for impaired language proficiency were also analysed.

\subsection{Language reception problems}

The difficulty to understand complex syntactic structures is by far the most common dysfunction which has been found in this study, affecting 11 (91.7\%) children. In general, children showed no problem decoding simple and compound sentences linked by coordinated 
Gloria Alvarez-Benito et al. - Cognitive and language-based disabilities...

conjunctions. In contrast, subordination tended to be more difficult to understand, the main problem being that children had difficulty to identify the relationship between the main clause and the subordinated clause: temporal, causal, conditional, consequence, purpose, etc.

Apart from the problem associated with the type of sentences already mentioned, children also proved to have difficulty in understanding the meaning of sentences that did not conform to the canonical word order. Any alteration or rearrangement of the elements in the sentence structure implied an additional effort on the part of the child to understand the message. For example, a sentence with the structure OVS (object-verb-subject) was harder to be processed and understood than an SVO structure, which follows the canonical sentence order.

Structural ambiguity was also a source of complexity. In this type of constructions, the same string of words may have more than one parse, which means the sentence has, at least, two possible interpretations. When children were exposed to structural ambiguity, they generally had no problem with one of the interpretations but it was difficult for them $(n=11,91,7 \%)$ to see the other possible reading(s):

(1) Los padres del niño y la niña vinieron a mi oficina.

[The parents of the boy and the girl came to my office]

When children were asked "who came to my office?" they answered "the parents of the boy and the girl" and when they were asked „how many people came to my office?”, their answer was „two, the father and the mother". In this interpretation „of the boy and the girl” is postmodifying the head of the Noun Phrase „parents”:

[The parents [of the boy and the girl]]

It was difficult for them to see another reading, even though they were told there were other possible interpretations. An explanation was necessary for them to understand that the answer for the second question could be three, the parents of the boy, on the one hand, and the girl, on the other hand. In this second interpretation, there is a 
coordination of two Noun Phrases, „the parents” (postmodified by „of the boy") and "the girl”:

[The parents [of the boy]] and [the girl]

Another interpretation could be that 4 people came to the office, namely the father and the mother of the boy, and the father and the mother of the girl20.

[The parents [of the boy]] and [the parents [of the girl]]

Children also had problems to see the two readings of the following example:

(2) El pollo está listo para comer.

[The chicken is ready to eat]

What they understood in example (2) was that "the chicken" was the object of the transitive verb „eat”. It was not until they were shown the picture in (3) that they understood the chicken could also be the subject of the verb "eat”, which in this case is used as a pseudointransitive verb, since the object is not expressed:

(3) The chicken is ready to eat.

Figure 1. The chicken is ready to eat

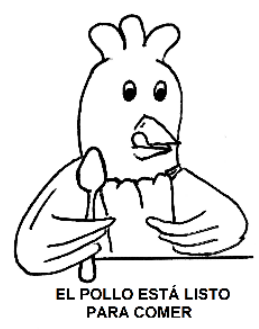

Source: Own work

Some difficulties regarding pragmatic issues were also found. In any interaction, much of the information communicated is implied

20 There are even some additional interpretations depending on the referents of the noun "parents” (Both the father and the mother, or just the mother, or just the father of the boy and /or the girl). 
Gloria Alvarez-Benito et al. - Cognitive and language-based disabilities...

rather that uttered. This means that the hearer must decode not only what is explicitly mentioned in the message but also what is implicit. In other words, the hearer has to „read between the lines”. To make the right interpretation of the message, the hearer needs to understand the words expressed in the utterance (locution), but also the speaker's intentions (illocution), and the context where the message is uttered. The data revealed that 8 children in our study $(66,7 \%)$ tended to use a type of literal decoding and, consequently they found it very difficult to understand implied, indirect or connotative meaning.

\subsection{Language production problems}

Five $(41.7 \%)$ of the assessed children exchanged consonants of words (commonly known as spoonerism), either in presence or in absence. The exchange showed up within the word itself ${ }^{*}$ marandina instead of mandarina) or it might involve the consonants in subsequent or close words, generally in the first syllable ${ }^{*}$ porro folar instead of forro polar):

(4) Hace mucho frío. Me voy a poner el porro folar.

[It is very cold. I am wearing my fleece]

This exchange, as noticed, took place at the syntagmatic level (in presence), since the letters exchanged were explicitly present in the words of the utterance. However, this consonant exchange also occurred in absence or at the paradigmatic level (pote instead of bote, potas instead of botas), consonants which were not clearly present in the sentence chain:

(5) Me ayudas a abrir el pote?

[Can you help me to open the jar?]

The exchange in presence turned out to be more frequent than the exchange in absence (70\% of the cases). Regarding exchange in absence, it is worthwhile to mention that the consonants involved in the exchange were close in articulation, mainly bilabials ( $p, b, m)$. In fact, bilabial consonants posed articulation problems for 3 (25\%) 
children. Another 3 (25\%) children inserted an intrusive consonant in a word (known as epenthesis) as an influence from the preceding or subsequent word (blota de plástico for bota de plástico), being the most typical inserted consonant letter "l”. Sometimes the syllables in a word were reorganised („hubo" instead of „buho” [owl]). In some cases, the new syllable arrangement tried to shape and sound like the preceding word: "que te has colao, calabao" instead of "que te has colao, $\underline{\text { bacalao"). }}$.

The lexical level was one of the most severely affected. 10 children (83.3\%) had difficulties in lexical access, in finding the correct words, mainly nouns (anomic aphasia) and verbs. The problem affected only their verbal behaviour while the nonverbal production remained generally intact. So, many children made use of compensation strategies ${ }^{21}$ such as hand gestures that corresponded to the object for which they could not find the name. Some cases of anomic aphasia were tough to diagnose because patients tended to replace the word they could not access with other semantically related terms. Thus, children tended to use general words like hyperonyms („árbol” [tree], „animal” [animal], "fruta" [fruit]) when they could not remember the hyponym, a type of the general word specified by the hyperonym („encina" [holm oak], „canguro" [kangaroo], „níspero" [loquat]).

Sometimes, children paraphrased when they needed to substitute a word they could not access. In these cases, a holonym, a term denoting the whole, preceded by a determiner plus „parte de” [part of], when the child could not remember the meronym. In most of these examples, the structure "determiner + part of + holonym" was followed by a modifying clause to specify meaning:

(6) Mmmm ... una parte del castillo que es alta y sirve para vigilar.

[Mmmm ... a part of the castle which is high and is used to watch]

Co-hyponyms were also a solution for the word the child could not recall: „whisky” [whisky] instead of „champán” [champagne], „can-

21 T. Y. Hsiao, R. L. Oxford, Comparing theories of language learning strategies: A confirmatory factor analysis, „The Modern Language Journal” 2002. 
Gloria Alvarez-Benito et al. - Cognitive and language-based disabilities...

guro" [kangaroo] for "gorila" [gorilla], „manzana” [apple] instead of „pera" [pear], or even "farola” [streetlight] for „lámpara" [lamp] etc.

Closely related to children's difficulties in accessing the correct words were the morphological changes observed in their utterances. Word derivation becomes an interesting indicator as children's use of prefixes and suffixes is quite peculiar. When children were asked to give an antonym of a word, they habitually created new words by using inappropriate prefixes, infixes or suffixes. For instance, they said improtegido (disprotected) instead of desprotegido (unprotected), or pescador (fisherman) instead of pescadero (fishmonger) or panadera (baker) instead of panera (bread basket). Another interesting morphological change was that children blended two different words such as for example estampida (stampede) and zambullida (dive) and produced estambullida (stampive).

\subsection{Wrong use of language in context}

As stated above, in order to communicate with others, speakers need to master purely linguistic as well as pragmatic aspects by displaying appropriate receptive and productive skills. We have seen that children diagnosed with CNS cancer not only have difficulties in understanding and using their language correctly but also show trouble when exposed to ambiguous use of the language. Similarly, being fluent in a language does not only mean to know the vocabulary and the rules of the grammar to combine those words into grammatical or correct sentences, but also to know how to use the language in context. The fact that a sentence is grammatical does not mean it is appropriate in every context, and $6(50 \%)$ children used well-formed sentences or expressions in the wrong context or situation, behaviour which is certainly related to their comprehension problems but also to lack of pragmatic competence. As a matter of fact, many of the examples recorded are related to Grice's Maxims ${ }^{22}$. Sometimes, chil-

22 H. P. Grice, Logic and conversation, [in:] P. Cole, J. Morgan (Eds.), Syntax and Semantics: Vol 3, speech acts. Academic Press, New York 1975. 
dren gave more information than required; while in other cases, their answer did not contain enough information (Maxim of Quantity). The Maxim of Relevance was often broken, too. When they were asked a question using a word we were sure they did not know children preferred to answer anything -in many cases not related to the question, instead of recognising that they did not understand. For example, when talking about sports, they were asked if there was disagreement (disparidad de opiniones) among their family members regarding the best football team. Because of their age, most of the children do not know the word disparidad. However, they avoided using that word and answered mentioning anything related to football.

They also showed problems related to politeness strategies ${ }^{23}$. Children were very direct in the way they spoke, so their utterances, although grammatically correct, sounded somehow impolite. For example, they tended to overuse imperatives, also when talking to older people; it seems they were not paying attention or simply were not conscious of how social relations are constructed. Unlike other type of errors (phonological, lexical, morphological), pragmatic misuses are not only considered linguistically incorrect but they are perceived as a social problem that hinder children's social acceptance and integration.

\subsection{Nonverbal strategies}

Their impaired command of the language is somehow counteracted with the use of nonverbal compensatory strategies. In fact, children showed a high use of hand gestures, as it has been mentioned at the beginning of this section. Three main types of gestures were found to be more frequently used: emblems, illustrators and adaptors, which are very different in nature and also differ in function ${ }^{24}$.

${ }^{23}$ P. Brown, S. C. Levinson, Politeness: Some universals in language usage. Cambridge University Press, Cambridge 1987.

${ }^{24}$ P. Ekman, W. V. Friesen, The repertoire of nonverbal behavior: Categories, origins, usage, and coding, [in:] A. Kendon (Ed.), Nonverbal communication, interaction, and gesture. Mouton Publishers, Den Haag 1981. 
Gloria Alvarez-Benito et al. - Cognitive and language-based disabilities...

Emblems are body gestures which can be translated into words and which are consciously and purposely performed. They can cooccur in synchrony with words with the same meaning or they can be used in isolation without the support of words. Children tried to compensate their lack of fluency with emblems, but also with illustrators. For example, one of the girls tried to describe a limousine although she was incapable of saying the word, but she tried to draw with her hand the long shape of this type of car long before she produced the word Swarovski.

Illustrators are signals that complement verbal messages, generally hand gestures and head and body movements. Apart from being used to complete, complement or modify a verbal message, they are said to increase the ability to remember. Most children with language problems felt very nervous when they had to interact with other people. This may be the reason why they used so many adaptors, that is to say, gestures, generally performed unconsciously, that satisfy personal needs and release the body tension but they do not provide meaning related to the verbal message. Some children touched their ear lobe or their nose, others covered their mouth or rubbed their forehead, or even coughed to feel more comfortable.

Another finding regarding nonverbal communication had to do with eye-contact. Children with more severe language problems avoided eye-contact what constituted a barrier for communication and, in consequence, for socializing. Not keeping visual contact is an obstacle to regulate the flow of communication, as it does not allow the speaker to express emotions. Additionally, it makes it very difficult to monitor feedback which probably impedes interpersonal relationships.

\subsection{Contrast of cognitive variables based on language-based disabilities}

Finally, the relationship between children's language-based disabilities and their cognitive abilities was analysed. In order to study 
the significant differences between dichotomous variables based on qualitative variables, a nonparametric Mann-Whitney $U$ test with Boostraping following the Monte Carlo simulation technique based on 10000 samples were carried out. These categorical variables have been created from the measures of language-based difficulties, pointing out the children who have difficulties in these different areas (e.g. lexical access, articulation, consonant exchange, etc.).

Figure 2. Cognitive statistically-significant differences concerning languagebased difficulties.

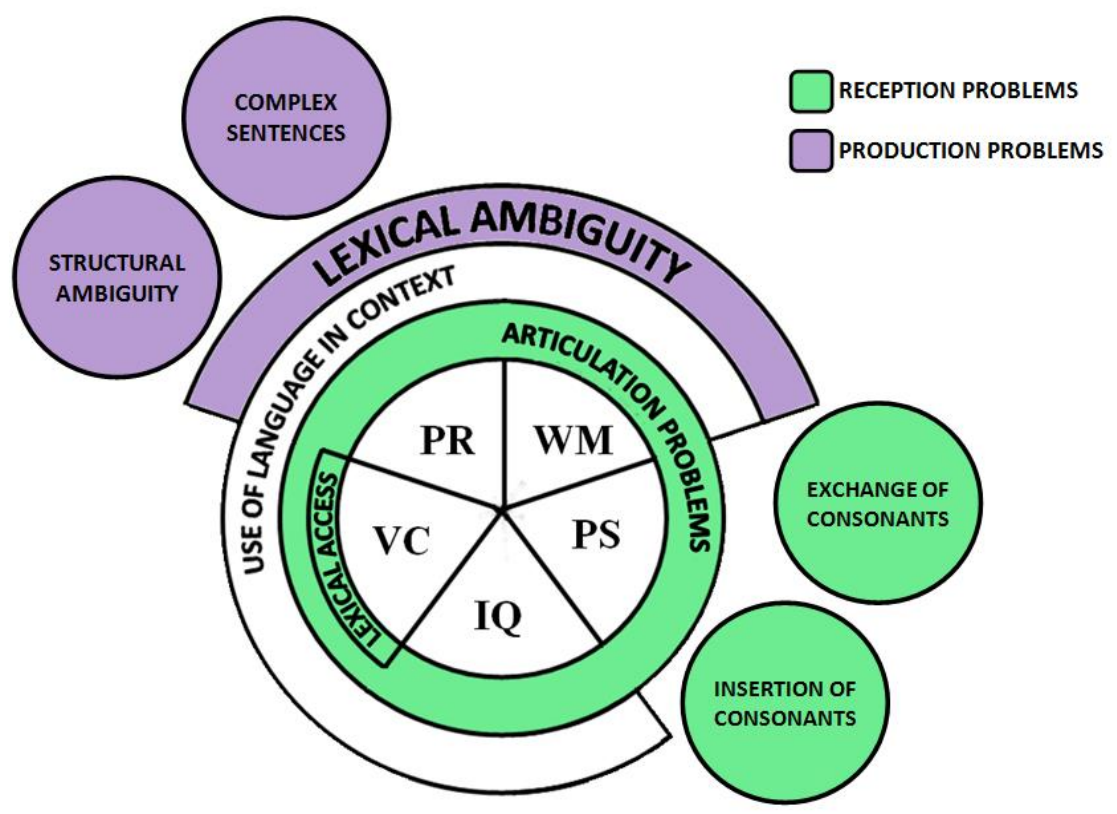

Note: IQ - Intelligence Quotient; VC - Verbal Comprehension; PR - Perceptual Reasoning; WM - Working Memory; PS - Processing Speed.

Source: Own work

Regarding the relation between the WISC scores and the languagebased difficulties, statistically significant differences have been found 
Gloria Alvarez-Benito et al. - Cognitive and language-based disabilities...

in $\mathrm{VC}$ in children with impaired lexical access $\left(\mathrm{U}_{\mathrm{MW}}=.50, \mathrm{p}=.004\right.$, $\mathrm{p}_{\mathrm{Mc}}=.045,99 \%$ IC $\left.[.039, .050]\right)$.

Difficulties in understanding lexical ambiguity is related to differences in PR ( $\mathrm{U}_{\mathrm{MW}}=4.00, \mathrm{p}=.041, \mathrm{p}_{\mathrm{Mc}}=.044,99 \%$ IC $\left.[.039, .049]\right)$ and $\mathrm{WM}\left(\mathrm{U}_{\mathrm{MW}}=3.50, \mathrm{p}=.033, \mathrm{p}_{\mathrm{Mc}}=.028,99 \%\right.$ IC $\left.[.023, .032]\right)$. The children with articulation problems show statistically significant differences in all cognitive variables (IQ: $\mathrm{U}_{\mathrm{MW}}=.000, \mathrm{p}=.013, \mathrm{p}_{\mathrm{Mc}}=, 008$, 99\% IC [.006, .011]; VC: $\mathrm{U}_{\mathrm{MW}}=.000, \mathrm{p}=.012, \mathrm{p}_{\mathrm{Mc}}=, 008,99 \%$ IC [.006, $.011]$; PR: $\mathrm{U}_{\mathrm{MW}}=.000, \mathrm{p}=.012, \mathrm{p}_{\mathrm{Mc}}=, 008,99 \%$ IC [.006, .011]; WM: $\mathrm{U}_{\mathrm{MW}}=.000, \mathrm{p}=.012, \mathrm{p}_{\mathrm{Mc}}=, 009,99 \%$ IC [.006, .011]; PS: $\mathrm{U}_{\mathrm{MW}}=3,000$, $\mathrm{p}=.048, \mathrm{p}_{\mathrm{Mc}}=, 066,99 \%$ IC $\left.[.060, .073]\right)$. Likewise, data about the wrong use of language in context show statistically significant differences with all WISC scores except PS (IQ: $\mathrm{U}_{\mathrm{MW}}=1.000, \mathrm{p}=.006$, $\mathrm{p}_{\mathrm{Mc}}=, 006,99 \%$ IC $[.004, .007]$; VC: $\mathrm{U}_{\mathrm{MW}}=4.000, \mathrm{p}=.024, \mathrm{p}_{\mathrm{Mc}}=, 024$, 99\% IC [.020, .028]; PR: $\mathrm{U}_{\mathrm{MW}}=.000, \mathrm{p}=.004, \mathrm{p}_{\mathrm{Mc}}=, 002,99 \%$ IC [.001, $.004] ; \mathrm{WM}: \mathrm{U}_{\mathrm{MW}}=5.000, \mathrm{p}=.037, \mathrm{p}_{\mathrm{Mc}}=, 038,99 \%$ IC $[.033, .042]$; PS: $\mathrm{U}_{\mathrm{MW}}=7,000, \mathrm{p}=.072, \mathrm{p}_{\mathrm{Mc}}=, 085,99 \%$ IC [.078, .092]). There are no significant differences in the cognitive variables regarding the problems children show with consonant exchange and consonant insertion, and also with children's difficulties to understand structural ambiguity and complex sentences.

\section{Discussion and conclusion}

Cancer survivors have been described as especially at risk for decreased quality of life due to a lack of supportive social network. Social networks, in turn, can be enhanced through the use of appropriate communication skills. Previous studies have extensively explored the side-effects of pediatric cancer on neurocognitive variables but language-dependent discourse abilities have not been sufficiently explored. This study contributes to the understanding of how discourse analysis offers interesting data needed to uncover language and communication problems which are not usually detected in a cognitive evaluation. 
Language-based disabilities found in this study clearly point to problems in social interaction skills: children's lack of eye contact, their unnecessary use of imperatives without adjusting their speech to the age of their interlocutor, their difficulties in lexical access, the excessive directness that could be understood as lack of politeness, or simply the fact of not recognising that they do have problems in understanding but going on talking on anything related to the topic mentioned are indicators of their communication disabilities.

Regarding cognitive variables, when age and sex were considered, no statistically-significant differences were found among the participants in this study. That is, children's performance in the cognitive tests did not depend on their age or sex. Generally speaking, most cognitive scores for the participants are consistently 1SD below the mean, except for PS which is 2SD below the normative mean. Their low scores in cognitive abilities, mainly in processing speed, evidence a possible slower rate of achievement, as already confirmed in previous studies 25 .

In addition, a close relationship between cognitive abilities and language-based difficulties is observed. As regards language reception difficulties, children with problems to understand lexical ambiguity got lower scores in PR and WM. Those that used wrong expressions because they did not understand the context or because they were not aware of their inappropriacy show low scores in cognitive scores such as PR, WM, VC and IQ. Thus, the relation between cognitive difficulties and the ability to use the language in the correct context appears to be out of question. Furthermore, their main difficulties are probably not only related to understanding language structure but to their ability to establish relationships between what has been heard, the expected reaction, how to express it and the best moment to do it. It is, doubtlessly, a complex process involving many factors that imposes a cognitive burden on these children. However, the difficulty to understand complex syntactic structures may generate many problems, for exam-

25 M. D. Ris et al. Measurement of developmental changes..., op. cit. 
Gloria Alvarez-Benito et al. - Cognitive and language-based disabilities...

ple, in exams (as described by some children in the interview). Children can sometimes be unable to answer an exam question because they do not understand what they have to do or what they are being asked, even though they have studied for the exam and they know the answer. This obviously would affect the child's self-esteem and academic performance.

As far as language production is concerned, there is one category which also shows a close relationship with all cognitive measures: problems with articulation -connected to letter sound processing. The children in this study have difficulties in articulating labial consonants with a near place of articulation; this fact makes them rival consonants, hindering the proper election and production. The multiple relations between articulation and cognitive abilities reveal that this is a language activity which requires a great cognitive effort. In fact, articulating words is the last step in a long process that needs the effort and concentration of the speaker. Firstly, the speaker has to formulate the semantic information of what he wants to say, then, he has to select the adequate words and activate the phonological information of those words; finally, he uses his motor system to articulate the sounds ${ }^{26}$. In our study, it seems that the children have managed to overcome all the stages, but problems arise in the last one; probably, because they were already making a big effort.

As regards the difficulties in lexical access observed in this study, they are connected with children's VC abilities. It seems an expected relation as the VC items measure the vocabulary knowledge the speaker needs in order to choose and retrieve the words needed.

The only cognitive factor not significantly related to languagebased problems is PS, which only shows a moderate relation with articulation problems. This fact does not necessarily imply that PS is not related to linguistic problems. Unlike this, being the PS mean in our sample 2SD under the norm, it seems that most of them show

26 X. Zhang, A. Samuel, Is speech recognition automatic? Lexical competition, but not initial lexical access, requires cognitive resources, "Journal of Memory and Language" 2018, s. 32. 
cognitive problems related to processing information. This is consistent with previous research ${ }^{27}$. Moreover, it has been shown that the loss of IQ points (mainly working memory and processing speed) is associated with a lower rate of learning, which subsequently affects children's academic performance. In our study, a direct relation between PS and language use has not been found, this may be due to the fact that PS has a mediating effect in the language performance, as it has been shown in studies of adult survivors of childhood brain tumour ${ }^{28}$.

Being aware of cognitive difficulties, there seems still a need to unravel language disabilities of children diagnosed with cancer. Through an interview it is possible to identify language-based problems which seriously affect children's academic performance and social well-being. In this way, discourse analysis provides key information for developing further remedial work with this population in order to diminish their communication and learning problems.

Finally, regarding the size of the sample, we would like to point out the special conditions of this population due to their delicate situation. Moreover, recent studies on brain cancer indicate low incidence rate both in men and women over 15 years, a male ratio of 7,9 (per 100,000 ) and 6,9 in women ${ }^{29}$, being cancer incidence rates usually lower in children. In fact, to our knowledge, there are no studies on the incidence rate in this population. These circumstances hinder data collection from larger sample sizes. Consequently, similar studies are needed to gain deeper knowledge of the language difficulties children with brain tumours suffer.

27 M. D. Ris et al., Measurement of neurodevelopmental changes..., op. cit.; M. A. de Ruiter et al., Neurocongnitive consequences..., op. cit.

${ }^{28}$ K. M. Smith, T. Z. King, R. Jayakar, \& R. D. Morris, Reading skill in adult survivors of childhood brain tumor: A theory-based neurocognitive model, „Neuropsychology" 2014

${ }^{29}$ A. Miranda-Filho et al., Cancers of the brain and CNS: global patterns and trends in incidence, „Neuro-Oncology” 2017. 
Gloria Alvarez-Benito et al. - Cognitive and language-based disabilities...

\section{Ethical approval:}

All procedures performed in studies involving human participants were in accordance with the ethical standards of the institutional and/or national research committee and with the 1964 Helsinki declaration and its later amendments or comparable ethical standards.

\section{Conflict of Interest:}

The authors declare that they have no conflict of interest.

\section{References:}

Bells S., Lefebvre J., Prescott S. A., Dockstader C., Bouffet E., Skocic J., Laughlin S., Mabbott D. J., Changes in white matter microstructure impact cognition by disrupting the ability of neural assemblies to synchronize, „Journal of Neuroscience" 2017, no. 37 (34).

Bressmann T., Speech Disorders Related to Head and Neck Cancer Laryngectomy, Glossectomy, and Velopharyngeal and Maxillofacial Deficits, [in:] J. S. Damico, N. Müller, M. J. Ball (Eds.), The Handbook of Language and Speech Disorders, Blackwell, Oxford 2010.

Brown P., Levinson S. C., Politeness: Some universals in language usage (Studies in interactional sociolinguistics, 4). Cambridge University Press, Cambridge 1987.

De Ruiter M. A., Van Mourik R., Schouten-Van Meeteren A. Y., Grootenhuis M. A., Oosterlaan J., Neurocognitive consequences of a paediatric brain tumour and its treatment: a meta-analysis. „Developmental Medicine \& Child Neurology" 2013, no. 55 (5).

Docking K., Munro N., Marshall T., Togher L., Narrative skills of children treated for brain tumours: The impact of tumour and treatment related variables on microstructure and macrostructure, „Brain Injury” 2016, no. 30 (8).

Docking K., Murdoch B., Suppiah R., The impact of a cerebellar tumour on language function in childhood, „Folia Phoniatrica et Logopaedica” 2007, no. 59 (4).

Ekman P., Friesen W. V., The repertoire of nonverbal behavior: Categories, origins, usage, and coding, [in:] A. Kendon (Ed.), Nonverbal communication, interaction, and gesture, Mouton Publishers, Den Haag 1981. 
Miranda-Filho A., Piñeros M., Soerjomataram I., Deltour I., Bray F., Cancers of the brain and CNS: global patterns and trends in incidence, „NeuroOncology" 2017, no. 19 (2).

Grice H. P., Logic and conversation, [in:] P. Cole, J. Morgan (Eds.), Syntax and Semantics: Vol 3, speech acts, Academic Press, New York 1975.

Gunn M. E., Mört S., Arola M., Taskinen M., Riikonen P., Möttönen M., Lähteenmäki P. M., Quality of life and late-effects among childhood brain tumor survivors: a mixed method analysis, „Psycho-Oncology” 2016, no. 25 (6).

Hardy K. K., Willard V. W., Allen T. M., Bonner M. J., Working memory training in survivors of pediatric cancer: a randomized pilot study, „Psycho-Oncology" 2013, no. 22 (8).

Hsiao T. Y., Oxford R. L., Comparing theories of language learning strategies: A confirmatory factor analysis, „The Modern Language Journal” 2002, no. 86 (3).

Novakovic B., Fears T. R., Wexler L. H., McClure L. L., Wilson D. L., McCalla J. L., Tucker M. A., Experiences of cancer in children and adolescents, "Cancer nursing” 1996, no. 19 (1).

Ott J. S., Webb T. E., Anderson C. A., Kastelic J. E., Krill Jr C. E., Childhood cancer and vulnerability for significant academic underachievement, „Journal of learning disabilities” 1982, no. 15 (6).

Ris M. D., Grosch M., Fletcher J. M., Metah P., Kahalley L. S., Measurement of neurodevelopmental changes in children treated with radiation for brain tumors: what is a true 'baseline?', „The Clinical Neuropsychologist” 2017, no. 31 (2).

Satariano S., The 'late effects' of paediatric brain tumours and the implications for education settings, „Educational \& Child Psychology” 2016, no. 33 (1).

Scantlebury N., Bouffet E., Laughlin S., Strother D., McConnell D., Hukin J., Fryer C., Laperriere N., Montour-Proulx I., KeeneD., Fleming A., Jabado N., Liu F., Riggs L., Law N., Mabbott D. J., White matter and information processing speed following treatment with cranial-spinal radiation for pediatric brain tumor, „Neuropsychology” 2016, no. 30 (4).

Schwartz R. G. (Ed.)., Handbook of child language disorders. Routledge, New York 2017.

Smith K. M., King T. Z., Jayakar R., Morris R. D., Reading skill in adult survivors of childhood brain tumor: A theory-based neurocognitive model, „Neuropsychology" 2014, no. 28 (3). 
Gloria Alvarez-Benito et al. - Cognitive and language-based disabilities...

Thompson G., Supporting Communication Disorders: A Handbook for Teachers and Teaching Assistants. David Fulton Publishers, London 2013.

Willard V. W., Cox L. E., Russell K. M., Kenney A., Jurbergs N., Molnar Jr A. E., Harman J. L., Cognitive and Psychosocial Functioning of Preschool-Aged Children with Cancer, "Journal of Developmental \& Behavioral Pediatrics" 2017, no. 38 (8).

Zhang X., Samuel A., Is speech recognition automatic? Lexical competition, but not initial lexical access, requires cognitive resources, „Journal of Memory and Language" 2018, no. 100.

Zou P., Conklin H. M., Scoggins M. A., Li Y., Li X., Jones M. M., Palmer S. L., Gajjar A., Ogg R. J., Functional MRI in medulloblastoma survivors supports prophylactic reading intervention during tumor treatment, „Brain imaging and behavior" 2016, no. 10 (1).

\section{Appendix 1.}

Protocol for the Semi-structured interview

\section{Personal data}

- What's your name?

- How old are you?

- When were you born?

- How many members are there in your family? How do you get on with your parents, your brothers, your sisters?

- How long ago did you finish your treatment?

- Please, tell me, what happened to you?

- Have you noticed any changes after treatment? (physical changes, feelings, ways of relating to others? )

- Let's change the topic. Which is the happiest moment of your life, that you can remember?

- What has been the best thing that has recently happened to you? (for instance, last week?) 


\section{Friends}

- Do you have many friends?

- How many? What are their names?

- Are they your classmates? Your parents' friends' sons or daughters?

- What do you normally do together?

- Who is your best friend?

- Do you do what your friends propose or do you decide what you're going to do?

\section{At school}

- How do you do at school?

- What about your teachers?

- What is your favorite subject? Why?

- Which subject do you like the least? Why?

- Do you have a lot of homework?

- Do you find your homework difficult to do?

- How do you feel when something is wrong or when you fail?

- Do you have any help with your homework? Who helps you? How many times per week?

- What do you normally do at school?

\section{Now, let's talk about things you would like to do in the future...}

- What job would you like to have?

- Do you think you can achieve it? Why?

- Why do you like this job?

- Do you need any help to get this desire for the future?

\section{Memories}

- What did you do last weekend? Did you get up early? Have you been with your friends? What did you eat? What have you done? Where have you been?

- What did you do last Christmas day?

- Do you take any medicine? Do you normally remember the medicine you need to take or does any family member remind you of it? 
Gloria Alvarez-Benito et al. - Cognitive and language-based disabilities...

\section{Desires}

- What is the greatest dream of your life?

\section{Sports}

- Do you like sports? Do you play any sport?

- When you're with your family, uncles, grandparents, friends, do they disagree on which football team is the best? 